23

\title{
Multimedia documents: towards a new paradigm for instructional technology
}

\author{
John F. Barrett \\ University of Southern Queensland \\ Toowoomba \\ Stephen J Craig-Smith \\ University of Queensland \\ Gatton
}

\begin{abstract}
This paper introduces an alternative approach to the development of multimedia packages for instruction and learning. The notion of information types in higher education and how such information is treated to provide instructional packages for open/distance learning is introduced. An electronic document processing approach is suggested and exemplified by reference to a multimedia CD-ROM package in tourism and hospitality management. The application of this approach to teaching and learning is illustrated and explained by means of a tourism planning role-play. The paper concludes by suggesting some future directions of development and research.
\end{abstract}

Main conference themes: distance learning, flexible learning, infrastructure, visions

Educational areas: higher education, further education, professional development

Study topics:

Secondary keywords: future developments, hypermedia, learning systems, multimedia, publishing 


\section{INTRODUCTION}

Over the past twenty years research studies have constantly supported the view that, in most cases, well designed computer based materials provide both an effective learning environment and an efficient instructional system. Especially in training situations computer based materials can reduce costs of bringing personnel to levels of minimal competency by lowering instructional time by between 20 and 70 percent when compared with traditional instruction [1]. However, developing high quality education and training materials for computer delivery remains a relatively difficult and costly process. Even with advanced authoring tools the production of Computer Aided Learning (CAL) and Multimedia (MM) courseware remains a major undertaking in terms of the development expertise required, costs associated with establishing a development laboratory/production centre and the extensive time span of most projects together with additional costs of packaging and delivery [2].

\section{In search of an alternative approach.}

If courseware is as effective as claimed, ways must be found to reduce production time and costs. An alternative approach should make more economical the capture of content, writing and preparing of scripts, authoring and inclusion of various media into an instructionally viable structure and delivery mechanism. Here 'delivery' covers media and communications conduits as well as learner usability.

This paper addresses problems associated with extending traditional, "paperbased' data storage and manipulation into more technologically advanced forms. It will illustrate an electronic document based solution through examples of developments appropriate to higher education with reference to a Read Only Compact Disc (CD-ROM) package in tourism and hospitality management and suggests a new approach to instructional technology development [3].

Whether the information is used in research, teaching and instruction, in libraries for the generation and distribution of scholarly information, in management or administrative systems or in business, industry or government, the underlying problems and issues are similar and in most cases the same. Computer based systems are now widely used for the creation, storage, distribution and retrieval of information (primarily 'dynamic' information). However, most of the world's information (95\%) including information pertinent to academic activity is still stored in hard copy. Of the remaining 5\% there is $3 \%$ in photographic (microfiche, microfilm) form and only $2 \%$ is computer based. Most analysts suggest that problems of information capture, storage, ease of use including re-usability of information between different platforms are reasons why the computing based figures remain so low. 
If the form of information covered by the $95 \%$ figure is examined, an interesting fact appears: most of the information is in the form of documents. Here document refers to the nature and structure of a 'block' (chunk) of information and in concrete terms is most commonly thought of as a sheet, or collection of sheets, of paper containing information. Documents store compound information. The Macquarie Dictionary defines a document as 'a written or printed paper furnishing information or evidence' which can be 'a legal or official paper, the term being derived from the Latin documentum meaning lesson or example'. Even though this definition does not apply strictly to electronic documents, aspects of document integrity and security and the instructional aspects of content are relevant to the interests expressed in this paper.

Outlined below is a review of the current state of electronic documents development and an analysis of its use in educational delivery from the University of Southern Queensland. Some exciting new developments in a state wide, open learning project in tourism are presented where interactive multimedia developments have revolutionized tourism teaching.

\section{THE QUEENSLAND OPEN LEARNING PROJECT}

The state of Queensland is as large as Great Britain, Germany and France combined, but with a population of just over 3 million people. While the major concentration of population is centred on the south coast corner around the state capital, the rest of the population is scattered thinly along $2000 \mathrm{~km}$ of sea board and across vast expanses of inland semidesert. Education and training must take note of these geographical realities and the state government has expended vast sums on distance education. One such initiation has been the Queensland Open Learning Project (QOLP) where particular attention was given to helping the needs of the tourism and hospitality industry which is rapidly developing as the states most significant income earner [4].

Materials for the QOLP were developed by a consortium of Queensland Universities with expertise in hospitality and tourism education under the central management of the University of Southern Queensland (USQ) which enjoys a substantial reputation for distance education development. Eighteen learning packages in tourism and hospitality management (around 2000 pages in total) were developed in consultation with instructional designers, project managers, and multimedia experts of the USQ Distance Education Centre (DEC).

Instructional materials formation builds on research and theory founded on the disciplines of Instructional Science and Cognitive Science together with evaluation data on the effectiveness of educational technology. Design and 
implementation is also founded on theory and practice in distance education. The numerous instructional characteristics are part of the information (content) structure and therefore remain an attribute of the instructional material whether it takes the form of a printed document or an electronic document.

The tourism and hospitality management packages have been developed to provide for both undergraduate courses and inservice professional development to managers in various tourism locations. Transfer of credit is reciprocal across all participating universities.

The quality of materials rested on the expertise of the content experts and writers from the contributing universities supported by instructional designers who addressed such design components as: goals, objectives, sequencing, instructional icon, media objects and special features. In such an extensive package involving disparate input project management played an important role in ensuring all components were produced on schedule and within budget. The basic package consists of print, audio and video components and the extension on CD-ROM is marketed as part of the normal offerings of the universities involved or through USQ Continuing Education.

A major difficulty with traditional CAL or multimedia is covering both large areas of content and developing decision making skills. The two areas of declarative knowledge and procedural knowledge together with managerial problem solving and decision making have been integrated in this package [5]. These two aspects have been addressed through development of an electronic document set and a simulation environment respectively. Explanation of the nature of these components is set out below.

\section{Electronic document development}

The development team paid special attention to the commonalty of the communication elements which integrate various types of information easily, provide for reusability and communication of information, have widespread applicability and are appropriate to teaching/learning needs and functions. These concerns were addressed by a combination of elements which can be constructed into an electronic document.

Recent electronic document technology employs a methodology which describes the elements and relationships, and hence the structures of a document. The various parts or objects which make up a document, are represented in a document descriptive language. The technology which exists for this process is founded on a new standard known as the Standard Generalised Mark-up Language (SGML) [6, 7]. SGML is an evolving and accepted standard for describing the purpose of a document's formation and communication, content structure and format. 
The tourism and hospitality project employed a commercial publishing software system, Interleaf 6 [Interleaf Inc. Waltham, Massachusetts] to generate the structured electronic material. This is an application software package which can operate under UNIX, MSDOS or Windows. Although specialist skills are required for Interleaf 6 processing, input is through normal word processing documents. Interleaf 6 is used to build and edit compound documents ready for printing and publishing on CD-ROM to comply with the established ISO9660 standard.

Through a further procedure the document is 'pressed' (compiled) using WorldView Press to become a hypertext document for viewing and exploration. The viewing tool, known as WorldViewer, is specific to a viewing platform (i.e. the hardware) thereby providing portability of the pressed document between UNIX, DOS, Windows or Macintosh environments.

To support the development of materials at the preproduction and production stages a total system is required incorporating: document management, standard document description (SGML), production tools (in this instance Interleaf 6) and document interconnectivity (Active Document technology) [8]. The Interleaf system has its Relational Document Manager (RDM) package which enables full document management covering the design, development and production process, to keep track of document changes and locations.

\section{Procedural simulation}

Procedural knowledge is covered by a simulation of situations in such areas as front office management, conference and convention management, and tourism planning. The presentation was built using the authoring language IconAuthor and contains video, audio, animation as well as question and answer handling and control. Various activities require problem solving and procedural decision making before situational feedback is forthcoming and progress continues.

The CD-ROM training and education package forms a decision support system. Users may commence by using the simulation or the electronic document set. However the simulation is designed to enable a user to seek information in the document set at any time thus providing a form of decision support for case studies. This design and technology was applied to case studies in tourism planning.

\section{TOURISM PLANNING CASE STUDIES}

An increasing number of tourism courses involve some analysis of the tourism planning process. The teaching of tourism planning lends itself to extensive 
computer application. As tourism planning usually involves the analysis of extensive data sets on local resources, existing land use conflicts, population trends, regional infrastructure and so on, the ability to recall any of this material on a computer screen at any one time has tremendous advantages. The planning process involves furthermore the generation of a series of differing scenarios and an analysis of likely end results. The ability to run different proposals across the existing data facilitates the learning process and greatly improves the students appreciation of the planning system.

The present multimedia program enables the student one of two very different geographical scenarios: an urban coastal location or a rural inland region. The student also has the choice of a proactive role (i.e. a consultant planner working for a potential developer) or a reactive role, that is a planner working for a local authority.

The development proposed for the urban coastal location is a three hundred room international five star hotel; the project for the rural location is a thirty room health resort. For either scheme the student can access information on the physical, human and cultural environments of the area together with information on any environmental or existing planning restrictions. Students have the freedom to manipulate their proposals to best suit the site, the local community and the environment. At any stage in the process students can access not only the relevant regional data, but also text on the planning process and environmental impact.

\section{QOLP materials delivery and usage}

Completed documents can be delivered on a network or on CD-ROM. It is important to note that CD-ROM is used as a convenient and economical storage device to hold a large document set (in the order of 650 megabytes) and provide an economical means of packaging and distribution.

For reasons of access and equity CD-ROM facilities are available on campus and in about 40 study centres of the Queensland Open Learning Network, another component of the QOLP. Access will inevitably increase as most machines will come complete with CD-ROM players.

The simulation has a Graphical User Interface (GUI) and tutorial assistance facilitating ease of interaction with data, video clips and Notepad or Report features. On the proforma provided in the note taking facility students prepare an interim report similar to a document presented to a subcommittee. This can be circulated electronically among other students for analysis and discussion and be part of formative assessment. The final planning report is produced by students drawing on their notes and entering them under the headings provided. The final report can be used for summative assessment by the lecturer. 
Interaction with the hypertext documents is by means of WorldViewer although this is 'opaque' to the user. The advantage of material running under WorldViewer relates not only to accessing the sheer volume of available information, but also to what can be done interactively with the information. Users can carry out full text and Boolean searches across selected or all documents if necessary; 'copy and paste' information to a word processor for completing a report, use electronic 'post-it' notes which can be indexed and reviewed, and use 'book marks' during a search session. The system has extensive online hypertext help and an easy to use interface.

\section{TOWARDS A NEW DEVELOPMENT PARADIGM}

Future developments should be seen in light of various merging and divergent technologies which will invariably affect the development and delivery of instructional materials and information support systems. The development environment established in this work is a network model-in contrast to a centralized/bureaucratic system or a 'cottage industry' arrangement. Materials are enhanced and produced under a networked 'value added' model of management and productivity. The key concept is that all objects are in electronic form allowing ease of input, manipulation and alternative flexible delivery. A number of research initiatives highlighted below provide a sample of converging technologies influencing developments in the area of electronic multimedia document or hypermedia which will predictably affect teaching/learning environments in higher education.

\section{Multimedia integration}

In the next stage of development multimedia elements (as objects) will be integrated into the electronic publishing document. This means that some existing paragraphs, now in text, will become a voice (audio) segment object and some figures, when activated, will become animated drawings or video clips, or later full-motion video. This then becomes a multimedia electronic document having all the characteristics (as set out above) for construction, modification, storage/retrieval and distribution [9].

\section{Structured document analysis of instructional design components}

While concurrently evaluating applications and developing the technology and delivery system, work continues on evaluation, research and theory of instruction system design. One current project by Barrett is the formulation of an Instructional Design Coding System based on an object oriented approach to 
identifying and describing the document elements in terms of their role and function in the instruction and learning process.

\section{Computer managed learning extensions}

Another recently commenced project focuses on transposing the DEC's highly successful CML system into an object oriented package. This will allow interactive $\mathrm{CML}$ to be incorporated in multimedia documents [10].

\section{Integration in teaching/learning environment}

At the broader instructional system level a team from the USQ Faculty of Education and DEC were granted a national, (1994) CAUT (Committee for the Advancement of University Teaching) grant to produce an 'Electronic Learning/Teaching Network' which will incorporate the technologies discussed here in a communication network for the teaching a sociology of education course in a highly interactive mode. The core content materials (i.e. lecture notes, study guides, readings etc.) are be provided in an information rich network of electronic documents and conferencing technologies encouraging individuals and groups in problem solving, analysis of evidence and discussion of issues [11]. An application for a 1996 CAUT grant aims to extend the tourism planning case studies by increasing content scope and difficulty, and include computer mediated communications components such as electronic mail, computer conferencing and audiographics.

\section{Integration in electronic performance enhancement system (EPES)}

The multimedia document system developed here can be readily adapted to configure an Electronic Performance Enhancement System (EPES). A feasibility study of a training and information provision for policing indicated the possibility of using the multimedia document platform to 'call-up' legal and management documents (e.g. procedure manuals, quality standards specifications, regulations, etc.) into multimedia electronic document set. In this process the training materials will remain in direct synchronization with an organization's document information base [12].

\section{SUMMARY}

The underlying methodologies and technologies presented in this paper provide a means to an end-without them this system could not be implemented; with them new multimedia electronic publishing can be achieved. To be effective for learning the technology must be employed within a justifiable educational framework and purpose. This paper has presented a methodology for 
designing, constructing and implementing a system to enhance teaching/learning, scholarship/research and management aspects in higher education. An exemplar of the model was presented in the area of tourism planning to demonstrate the viability of this approach. By focusing on the core distribution of educational information via electronic multimedia documents and indicating areas of current development and future exploration, the paper has shown how teaching functions and learning environments in contemporary university education can become more efficient and more effective.

\section{REFERENCES}

1. Taylor, J. C., Kemp, J. E. and Burgess, J. V. (1993) Mixed-mode Approaches to Industry Training: Staff Attitudes and Cost Effectiveness. DEET, AGPS, Canberra.

2. Barrett, J. F. and Tan, W. (1992) Productivity Problems and Some Technological Solutions in the Design and Development Process. Proceedings of Information Technology for Training and Education Conference, Brisbane.

3. Barrett, J. F. (1993) Print to Multimedia on CD-ROM: a model for design and development. ASCILITE'93 Proceedings UNE. (ed. Lo, B.).

4. Craig-Smith, S. J., French, C. N. and Davidson, M. (1994) The Future of Hospitality and Tourism Education in Australia. National Tourism and Hospitality Conference. B.T.R. Canberra (forthcoming)

5. Barrett, J. F. (1994) Multimedia publishing-Systems design and development methodology for Open/Distance Learning. Proceedings of Open Learning '94,

6. Martin, B. (1988) SGML: An Authors Guide to the Standard Generalised Markup Language. Addison-Wesley Publishing Company, UK.

7. van Herwijnen, E. 1990 Practical SGML. Kluwer Academic Publishers, USA.

8. Barrett, J.F. (1992) Developing and Distributing Instructional Materials through an Active Document Approach. Proceedings of ASCILITE'92 (ed. Chia et al) Sydney. 
9. Barrett, J. F. (1994) Electronic publishing and the development of multimedia learning materials. Technology in Higher Education Conference, Sydney.

10. Barrett, J. F. and O'Mara, F. (1994) An Object Oriented approach to analysis, design and development of CML. Proceeding of APITITE Conference, Brisbane.

11. Naidu, S. and Barrett, J. F (1985) Enhancing Instructional Effectiveness with Computer Mediated Communications. Proceedings of the 17th World Congress of the International Council for Distance Education, UK.

12. Barrett, J. F. (1994) WorldView with Multimedia for Decision Support Systems. Interleaf International Users Conference, San Diego. 